Provided for non-commercial research and education use. Not for reproduction, distribution or commercial use.

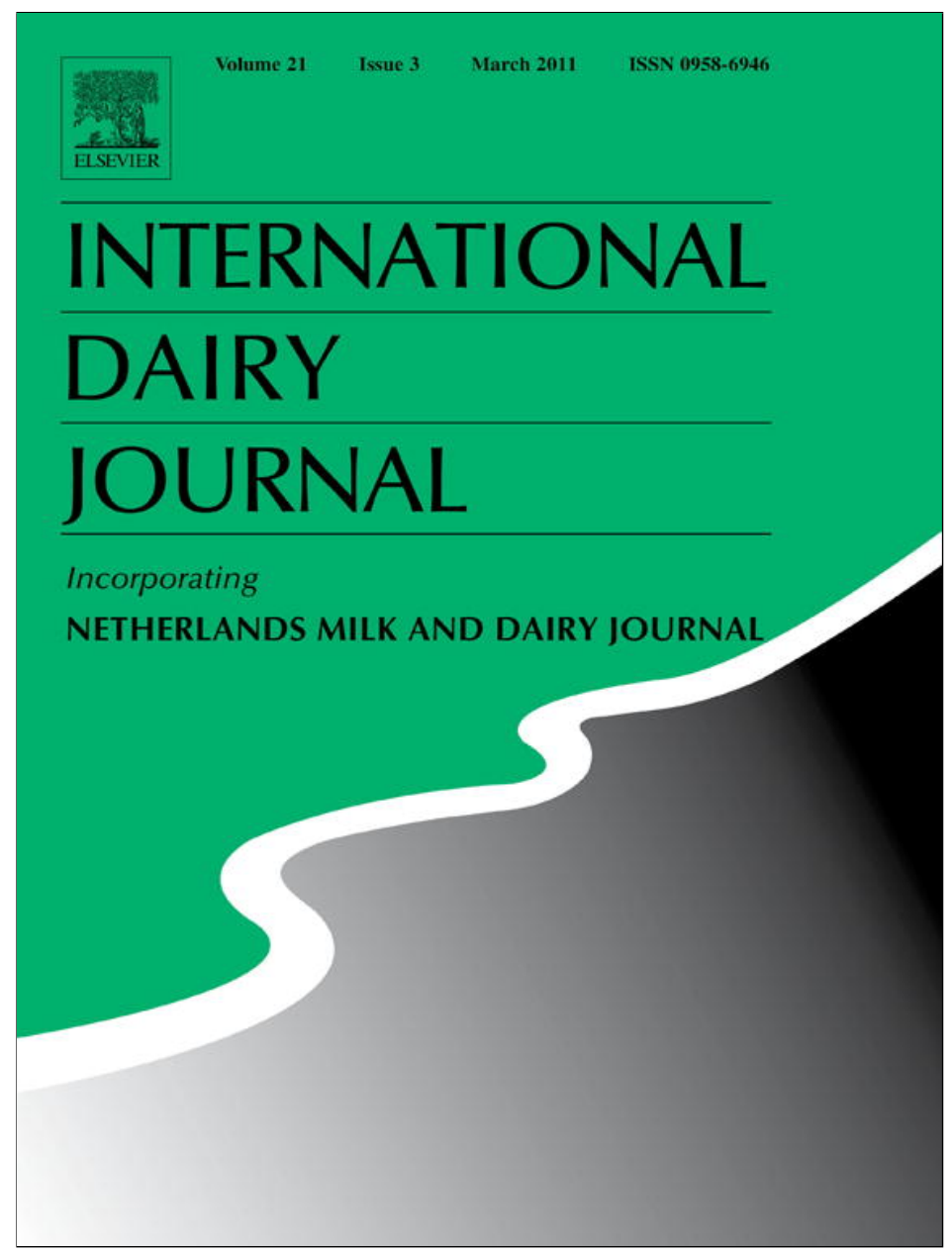

This article appeared in a journal published by Elsevier. The attached copy is furnished to the author for internal non-commercial research and education use, including for instruction at the authors institution and sharing with colleagues.

Other uses, including reproduction and distribution, or selling or licensing copies, or posting to personal, institutional or third party websites are prohibited.

In most cases authors are permitted to post their version of the article (e.g. in Word or Tex form) to their personal website or institutional repository. Authors requiring further information regarding Elsevier's archiving and manuscript policies are encouraged to visit:

http://www.elsevier.com/copyright 


\title{
Characterization of galactooligosaccharides produced by $\beta$-galactosidase immobilized onto magnetized Dacron
}

\author{
David F.M. Neri ${ }^{\mathrm{a}, \mathrm{b}, *}$, Victor M. Balcão ${ }^{\mathrm{a}}$, Susana M. Cardoso ${ }^{\mathrm{c}}$, Artur M.S. Silva $^{\mathrm{d}}$, \\ Maria do Rosário M. Domingues ${ }^{\mathrm{d}}$, Duarte P.M. Torres ${ }^{\mathrm{a}}$, Lígia R.M. Rodrigues ${ }^{\mathrm{a}}$, \\ Luiz B. Carvalho Jr. ${ }^{b}$, José A.C. Teixeira ${ }^{a}$ \\ a IBB-Institute for Biotechnology and Bioengineering, Centre of Biological Engineering, Universidade do Minho, Campus de Gualtar, P-4710-057 Braga, Portugal \\ ${ }^{\mathrm{b}}$ Departamento de Bioquímica and Laboratório de Imunopatologia Keizo Asami, Universidade Federal de Pernambuco, Brazil \\ ${ }^{\mathrm{C}}$ CERNAS/Agrarian Superior School, Institute Polytechnic of Coimbra, 3040-316 Coimbra, Portugal \\ ${ }^{\mathrm{d}}$ Department of Chemistry \& QOPNA, University of Aveiro, P-3810-193 Aveiro, Portugal
}

\section{A R T I C L E I N F O}

\section{Article history:}

Received 9 June 2010

Received in revised form

19 October 2010

Accepted 25 October 2010

\begin{abstract}
A B S T R A C T
Bioconversions using enzymes immobilized in magnetic supports present significant advantages due to the easy separation of the enzyme from the reaction mixture and the simplicity and low cost of the support preparation. The characterization of the oligosaccharide mixture obtained by the action of $\beta$-galactosidase covalently attached, via glutaraldehyde, to a hydrazide-Dacron-magnetite composite is presented. The fractionation of the oligosaccharide mixture by high performance liquid chromatography, followed by the analysis of the purified compounds by mass spectrometry and nuclear magnetic resonance spectroscopy permitted the identification of glucose, galactose, lactose and a hexose disaccharide containing a $1 \rightarrow 6$ linkage. Also, the following GOS were identified: $\beta$-D-Galp-( $1 \rightarrow 6)-\beta$-D-Galp- $(1 \rightarrow 4)$ Glcp, $\beta$-D-Galp-( $1 \rightarrow 4)$-[ $\beta$-D-Galp- $(1 \rightarrow 6)]$-Glcp and $\beta$-D-Galp- $(1 \rightarrow 6)-\beta$-D-Galp-( $1 \rightarrow 6)-\beta$-D-Galp- $(1 \rightarrow 4)-$ Glcp. When GOS yield (26.2\%) and kinetics of biotransformation of lactose by the Dacron immobilized $\beta$-galactosidase were compared with values obtained for the enzyme immobilized in other magnetic supports, similar behaviour was observed.
\end{abstract}

(c) 2010 Elsevier Ltd. All rights reserved.

\section{Introduction}

The production of galactooligosaccharides (GOS), like other oligosaccharides, is becoming of increasing interest, as their beneficial effects on human health have been recognized by several authors (Boehm \& Stahl, 2007; Maischberger et al., 2008). Oligosaccharides can be produced from natural polysaccharides (e.g., inulin, starch) by chemical or enzymatic hydrolysis, and can also be synthesized from smaller saccharides or by reverse hydrolysis reactions. In addition, reverse hydrolysis reactions, using glycosidases and glycosyltransferases may be employed (Mussatto \& Mancilha, 2007).

When lactose is used as the starting material, a group of nondigestible carbohydrates known as GOS are synthesized by the action of $\beta$-galactosidase. GOS contain one or no glucose molecule and one to six galactose molecules bound by different glycosidic

\footnotetext{
* Corresponding author. Departamento de Bioquímica and Laboratório de Imunopatologia Keizo Asami, Universidade Federal de Pernambuco, Brazil. Tel.: +351 253604406; fax: +351 253678986.

E-mail address: davidfmneri@yahoo.com.br (D.F.M. Neri).
}

bonds such as $\beta-(1 \rightarrow 2), \beta-(1 \rightarrow 3), \beta-(1 \rightarrow 4)$ and $\beta-(1 \rightarrow 6)$. Mixtures of oligosaccharides of various chain length and glycosidic bonds are formed during production (Alander et al., 2001; Ito et al., 1993; Tannock et al., 2004). Considerable amounts of unreacted lactose and monossarides are always present as transgalactosylation has to compete with hydrolysis (Mahoney, 1998; Maischberger et al., 2008).

Optimization of the best conditions for the production of GOS by the action of $\beta$-galactosidases requires the screening of enzymes that favour trangalactosylation and the selection of the corresponding reaction conditions (Cheng, Duan, \& Sheu, 2006; Gänzle, Haase, \& Jelen, 2008). These conditions and the enzymes used will establish the linkage between the galactose units, the efficiency of transgalactosylation and the components in the final products. Glycosidic bonds between two galactose units are mainly $\beta$ - $(1 \rightarrow 4)$ bonds when $\beta$-galactosidases derived from Bacillus circulans (Mozaffar, Nakanishi, Matsuno, \& Kamikubo, 1984) or Cryptococcus laurentii (Ozawa, Ontsuka, \& Uchidat, 1989) are used, and $\beta-(1 \rightarrow 6)$ bonds when enzymes derived from Aspergillus oryzae or Streptococcus thermophilus (Ito et al., 1990) are used.

$\beta$-Galactosidase for lactose hydrolysis or GOS production has been immobilized on different magnetic supports, including 
polysiloxane-polyvinyl alcohol magnetic particles (mPOS-PVA) (Neri et al., 2008, 2009a), magnetic poly(glycidylmethacrylate and methylmethacrylate) particles (Bayramoglu, Tunali, \& Arica, 2007), magnetic polysiloxane-polyaniline particles (mPOS-PANI) (Neri et al., 2009b) and thermo-sensitive magnetic hydrogel microspheres (Kondo \& Fukuda, 1997). As for non-immobilized enzymes, the predominant reaction products are trisaccharides, namely $4^{\prime}$ - or 6 '-galactosyllactose, and longer oligosaccharides consisting of 4 or more monosaccharide units (Albayrak \& Yang, 2002; Li, Xiao, Lu, \& Li., 2008; Shin, Park, \& Yang, 1998). Substantial amounts of transgalactosylated disaccharides are also produced in these reactions (Ishikawa et al., 1995; Ito et al., 1990). As expected, the immobilization process also plays an important role on the overall composition of the final GOS mixture (Sako, Matsumoto, \& Tanaka, 1999).

In the present study, the chemical characterization of a GOS mixture obtained by the action of $\beta$-galactosidase covalently attached, via glutaraldehyde, to a hydrazide-Dacron-magnetite composite is presented. Bioconversion process kinetics and yield were evaluated and compared with previously obtained data for $\beta$-galactosidase immobilized in different magnetic supports.

\section{Materials and methods}

\subsection{Hydrazinolysis of Dacron and magnetization}

Hydrazinolysis of Dacron (Terphane, Inc., Cabo, Brazil) and magnetization were obtained according to Carneiro-Leão, Oliveira, and Carvalho Jr. (1991), with the modifications implemented by Amaral, Carneiro-da-Cunha, Carvalho Jr., and Bezerra (2006). The magnetic hydrazide-Dacron obtained was filtered under vacuum and washed exhaustively with distilled water until pH 7.0, dried at $105{ }^{\circ} \mathrm{C}$ overnight and sieved $(<100 \mu \mathrm{m})$.

\section{2. $\beta$-Galactosidase immobilization}

Magnetic hydrazide-Dacron particles $(100 \mathrm{mg}$ ) were treated with glutaraldehyde according to Neri et al. (2009b). Activated magnetic hydrazide-Dacron particles were washed with distilled water 10 times and incubated overnight with $10 \mathrm{~mL}$ of $\beta$-galactosidase from A. oryzae $\left(0.72 \mathrm{mg} \mathrm{mL}^{-1}\right.$ ) (Sigma, Tokyo, Japan). The magnetic- $\beta$-galactosidase-Dacron preparation was then washed 10 times with $20 \mathrm{~mm}$ citrate-phosphate buffer, $\mathrm{pH} 4.5$ and kept in this buffer at $4{ }^{\circ} \mathrm{C}$ until use.

\subsection{GOS production}

The kinetics of GOSs formation were studied as follows: lactose (Sigma, Munich, Germany) solutions of increasing concentration ( 5 , $10,20,30,40$ and $50 \%, \mathrm{w} / \mathrm{v}$ ) prepared in $20 \mathrm{~mm}$ citrate-phosphate buffer solution, $\mathrm{pH} 4.5$, were added $(10 \mathrm{~mL})$ to the immobilized enzyme preparation (100 $\mathrm{mg}$ ) and samples were taken from 5 to 720 min and analyzed for sugar content by high performance liquid chromatography (HPLC).

The reaction kinetics were studied at four different temperatures $\left(30,40,50\right.$, and $\left.60{ }^{\circ} \mathrm{C}\right)$. GOS yield value was obtained by dividing the total weight of GOS produced by the weight of lactose consumed and multiplying by 100 . The reaction medium at different conditions for GOS production was under orbital stirring at $20 \mathrm{rpm}$.

\subsection{Sugar analysis by HPLC}

Sugar analysis were determined according to Neri et al. (2009a), exept that the column used was substituted from MetaCarb $67 \mathrm{H}$ to MetaCarb 87H (Varian Inc., Palo Alto, CA, USA). The response of the refractive index detector was recorded and integrated using the Star Chromatography Workstation software (Varian Inc.). The accuracy of the analysis was verified by determining mass balance of the sugars.

\subsection{Retention of activity}

The retention of activity of the immobilized enzyme was evaluated by incubation for another 10 times. The immobilized enzyme derivative was washed five times with $20 \mathrm{~mm}$ citrate-phosphate buffer, $\mathrm{pH} 4.5$, between each successive use.

\subsection{GOS fractionation}

Fractionation of the different trisaccharides and tetrasaccharides was achieved using the methodology of Dias et al. (2009). The HPLC system (Jasco, Tokyo, Japan) was further equipped with a Prevail Carbohydrate ES column $(5 \mu \mathrm{m}, 250 \times 4.6 \mathrm{~mm}$, Alltech, Deerfield, IL, USA). A mixture of acetonitrile and $0.04 \%$ ammonium hydroxide in water $(70 / 30, v / v)$ was used as eluent at a flow rate of $0.9 \mathrm{~mL} \mathrm{~min}^{-1}$. Reaction solution $(20 \mu \mathrm{L} 20 \%, \mathrm{w} / \mathrm{v}$, initial lactose concentration, $\mathrm{pH} 4.5,40^{\circ} \mathrm{C}$, after $29 \mathrm{~h}$ ) was injected. The refractive index (RI) signal was recorded and four fractions (3, 4, 5 and 6 ) were collected manually. The fractions were analyzed by mass spectrometry and, fractions 4,5 and 6 were analyzed by nuclear magnetic resonance (NMR) spectroscopy.

\subsection{Analysis of GOS by mass spectrometry}

Positive-ion mass spectra (MS) using electrospray ionization (ESI), ESI-MS and product ion spectra (ESI-MS/MS) of the ions observed in the ESI-MS, were obtained using an LXQ ion-trap mass spectrometer (Thermo Finningan, San Jose, CA, USA). For ESI analysis, oligosaccharide fractions were dissolved in methanol/water/ formic acid (50:50:0.1, by vol). Samples were introduced at a flow rate of $5 \mu \mathrm{L} \mathrm{min}^{-1}$ and the voltage applied was $5.5 \mathrm{kV}$. Nitrogen was used as the nebulizing and the drying gas. The heated capillary was kept at $350^{\circ} \mathrm{C}$. In each experiment, the ion transmission parameters were optimized automatically to improve the detection of the analyte of interest. Full scan mass spectra ranging from $\mathrm{m} / \mathrm{z} 100$ to 1500 were acquired in the positive mode. In the $\operatorname{MS}^{n}(n=2,3)$ experiments, collision energy varying 20 and 25 of normalized collision energy.

\subsection{Analysis of GOS by NMR}

The NMR structural characterization of the GOS mixture was done as described by Dourado, Cardoso, Silva, Gama, and Coimbra (2006). ${ }^{1} \mathrm{H}$ and ${ }^{13} \mathrm{C}$ NMR spectra were recorded in $\mathrm{D}_{2} \mathrm{O}$ on a Bruker Avance 500 spectrometer (Wissemboug, France) operating at 500.13 and $125.77 \mathrm{MHz}$, respectively, the chemical shifts expressed in $\delta(\mathrm{ppm})$ values relative to sodium trimethylsilyl2,2,3,3- $\mathrm{d}_{4}$-propionate (TSP-d4) as external reference. Lactose was used as a reference compound for the structural elucidation of GOS.

\subsection{Statistical analyses}

Results correspond to the mean of three independent experiments. Evaluation of the experimental data indicated that the error associated with each data point did not exceed $5 \%$. 
Table 1

Comparison of GOS yield produced by free and immobilized enzymes.

\begin{tabular}{|c|c|c|c|c|c|c|c|}
\hline \multirow[t]{2}{*}{$\begin{array}{l}\text { Source of } \\
\text { enzyme }\end{array}$} & \multicolumn{4}{|c|}{ GOS yield } & \multicolumn{2}{|c|}{$\begin{array}{l}\text { Reaction } \\
\text { conditions }\end{array}$} & \multirow[t]{2}{*}{ Reference } \\
\hline & $\%$ & $\left(\mathrm{~g} \mathrm{~L}^{-1}\right)$ & $\%$ & $\left(\mathrm{~g} \mathrm{~L}^{-1}\right)$ & $\%\left({ }^{\circ} \mathrm{C}\right)$ & $\mathrm{pH}$ & \\
\hline Aspergillus & 26.2 & 131.0 & 26.1 & 130.1 & 50 & 04.5 & This study \\
\hline \multirow[t]{3}{*}{ oryzae } & 26.0 & 129.9 & 26.1 & 130.1 & 50 & 04.5 & Neri et al., 2009a ${ }^{a}$ \\
\hline & 25.7 & 128.6 & 26.1 & 130.1 & 50 & 04.5 & Neri et al., 2009b \\
\hline & 25.5 & 51.0 & 22.6 & 45.2 & 20 & 04.5 & Gaur et al., 2006 ${ }^{\mathrm{C}}$ \\
\hline $\begin{array}{l}\text { Pectinex } \\
\text { Ultra SP-L }\end{array}$ & 15.8 & 47.4 & 12.8 & 38.4 & $3055-6$ & $04.0-5.0$ & $\begin{array}{l}\text { Aslan \& Tanriseven, } \\
2007^{\mathrm{d}}\end{array}$ \\
\hline Bacillus sp. & 41.0 & 147.6 & 43.0 & 154.8 & 36 & 55.0 & Cheng et al., $2006^{\mathrm{e}}$ \\
\hline
\end{tabular}

a Magnetic polysiloxane-polyvinyl alcohol.

b Magnetic polysiloxane-polyaniline particles.

c Covalent coupling to chitosan.

d Eupergit C.

e Chitosan.

\section{Results and discussion}

\subsection{GOS formation}

In the present study, the activity of the $\beta$-galactosidase from A. oryzae immobilized on magnetized Dacron with $31 \mathrm{mg}$ of protein $\mathrm{g}^{-1}$ of support (which was the maximum immobilization capacity of the support) resulted in the production of two types of GOSs, triand tetrasaccharides (fractions 4,5 and 6), with maximum concentrations of $20.2 \%$ and $5.9 \%(\mathrm{w} / \mathrm{v})$, respectively after $4 \mathrm{~h}$. Only one type of GOS was obtained by Gaur, Pant, Jain, and Khare (2006) with the same enzyme immobilized in chitosan, and these were trisaccharides with maximum concentrations of $25.5 \%$ after $12 \mathrm{~h}$. The prevalence of trisaccharides is in accordance with the literature data reported for the synthesis of GOSs by $\beta$-galactosidase from various origins (Albayrak \& Yang, 2002; Hsu, Lee, \& Chou, 2007; Li et al., 2008).

Table 1 presents values for maximum GOS concentration $\left(\mathrm{g} \mathrm{L}^{-1}\right)$ and corresponding GOS yield (\%) obtained using free and immobilized enzyme in different supports. It is clear that no significant differences were observed in GOS yield when $A$. oryzae $\beta$-galactosidase was used in its free form or immobilized in different magnetic supports. These results confirm the excellent accessibility of the substrate to the immobilized enzyme when magnetic supports are used for its immobilization, suggesting that events such as diffusion, mass transfer, steric and conformational changes do not interfere with the interaction with the enzyme substrate and do not reduce enzyme activity (Bayramoglu et al., 2007; Neri et al., 2009a, 2009b).

In light of this, not surprisingly, the results concerning the kinetics of GOS formation, the effect of lactose initial concentration

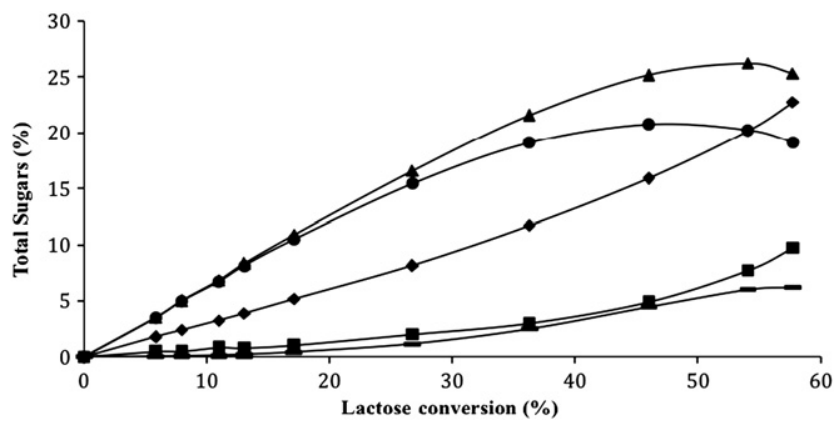

Fig. 1. Formation and degradation of GOS during lactose conversion by immobilized $A$ oryzae $\beta$-galactosidase on magnetized Dacron. The reaction was performed at $40{ }^{\circ} \mathrm{C}$ and $\mathrm{pH} 4.5$ and initial lactose concentration of 50\%: $\mathbf{\Lambda}, \mathrm{GOS} ; \bullet$, glucose; $\boldsymbol{\square}$, galactose; ๑, trisaccharides; - , tetrasaccharides. Results varied within 1 and $5 \%$.
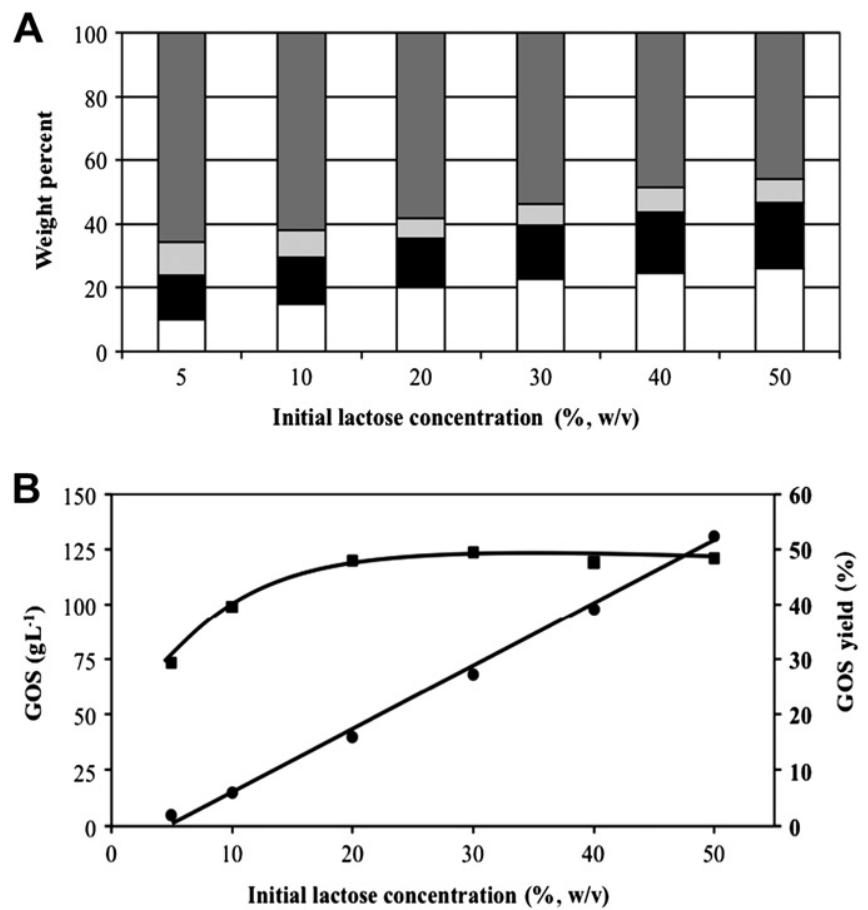

Fig. 2. Effect of the initial lactose concentration on the composition of saccharide mixture ( $\square$, GOS; $\square$, glucose;, galactose; $\square$, lactose) at (A) the maximum yield of GOS and (B)the relationship expressed in terms of $(\mathbf{0})$ total GOS $\left(\mathrm{g} \mathrm{L}^{-1}\right)$ and $(\boldsymbol{\square})$ maximum GOS yield. Production catalyzed by immobilized $A$. oryzae $\beta$-galactosidase on magnetized Dacron $\left(40{ }^{\circ} \mathrm{C}, \mathrm{pH} 4.5\right)$. Results varied within 1 and $5 \%$.
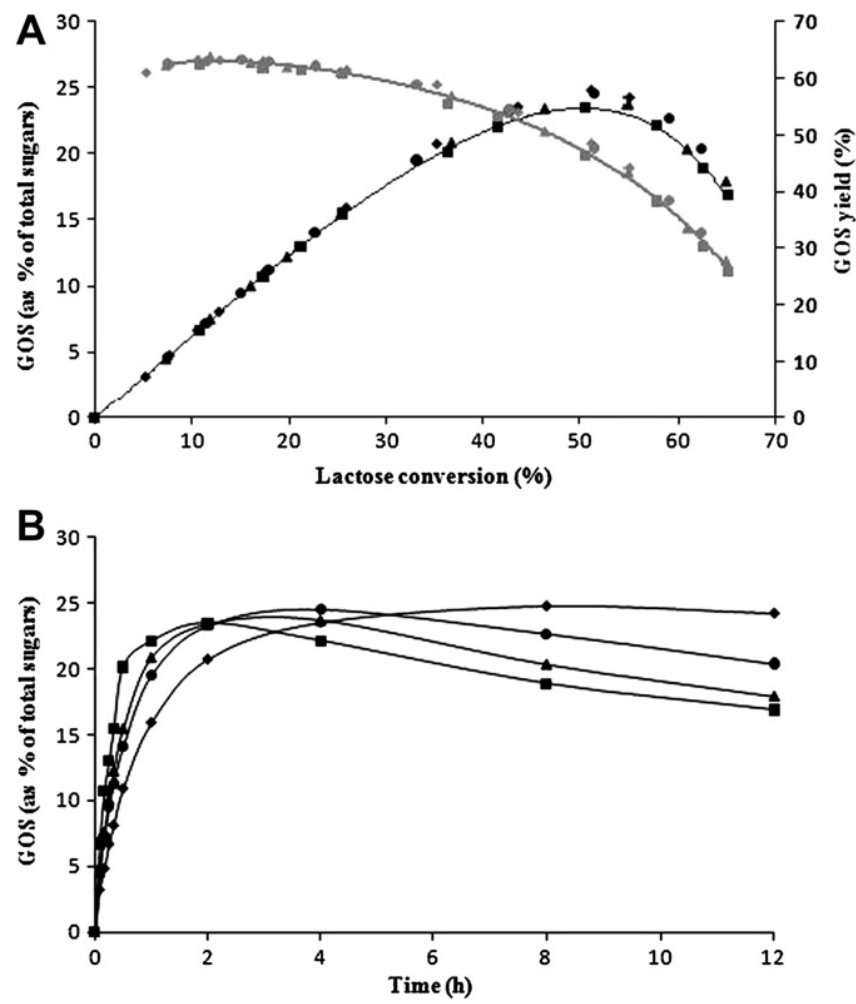

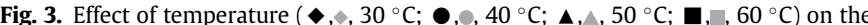
GOS production (black symbols, expressed as a percent of total sugars; grey symbols, percentage GOS yield) from the hydrolysis of $40 \%(\mathrm{w} / \mathrm{v})$ lactose catalyzed by immobilized $A$. oryzae $\beta$-galactosidase on magnetized Dacron: (A) GOS production versus lactose consumption; (B) time course of GOS production $\left(\bullet, 30^{\circ} \mathrm{C} ; \bullet, 40^{\circ} \mathrm{C} ; \boldsymbol{\Lambda}, 50^{\circ} \mathrm{C}\right.$; घ, $60{ }^{\circ} \mathrm{C}$ ). Results varied within 1 and $5 \%$. 
and temperature on GOS production and yield are similar to those reported for the same enzyme immobilized in other magnetic supports MPOS-PVA and MPOS-PANI authors to define these abbreviations (Neri et al., 2009a, 2009b). Figs. 1-3 represent the effect of these parameters on GOS production. Overall, the maximum GOS content in the product changed from $10.1 \%$ at $34 \%$ lactose conversion (initial lactose concentration 5\%) to $26.2 \%$ at $54.1 \%$ lactose conversion (initial lactose concentration 50\%). Moreover, as the initial lactose concentration increased from $5 \%$ to $50 \%$, the trisaccharide content doubled, from $9.4 \%$ to $20.7 \%$, while tetrasaccharides increased by 6.9 -fold, from $0.9 \%$ to $6.2 \%$. Temperature (between 30 and $60^{\circ} \mathrm{C}$ ) had no relevant effect on GOS yield while higher initial rates of GOS production were obtained as temperature was increased. However, no differences on the amount of total GOS produced were observed for temperatures between 40 and $60{ }^{\circ} \mathrm{C}$ after $2 \mathrm{~h}$ of reaction, a similar behaviour to that described by Martínez-Villaluenga, Cardelle-Cobas, Corzo, Olano, and Villamiel (2008) for $\beta$-galactosidase from Kluyveromyces lactis.

\subsection{Re-use of magnetized DACRON on lactose hydrolysis}

One of the key advantages of enzyme immobilization on magnetic support is its straight forward re-utilization (Kondo \& Fukuda, 1997). However, the successful application of this advantage requires that the enzyme retains its activity for as many uses as possible. For the particular case of Dacron, the re-use was assayed for up to 10 cycles at $25^{\circ} \mathrm{C}$ with lactose $(20 \%, \mathrm{w} / \mathrm{v})$ as substrate. The enzyme retained $90 \%$ of its initial activity after ten uses (date not shown), a result similar to what has been previously reported (Neri et al., 2009a, 2009b). Other supports evaluated include entrapped

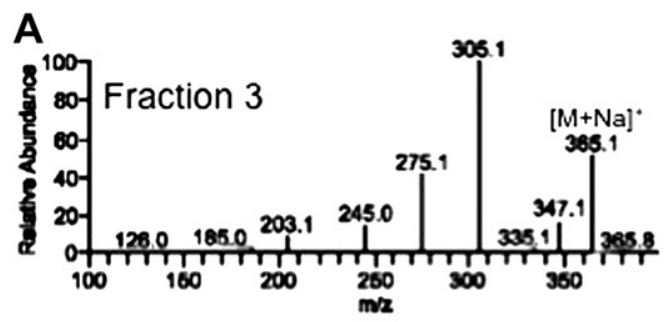

B
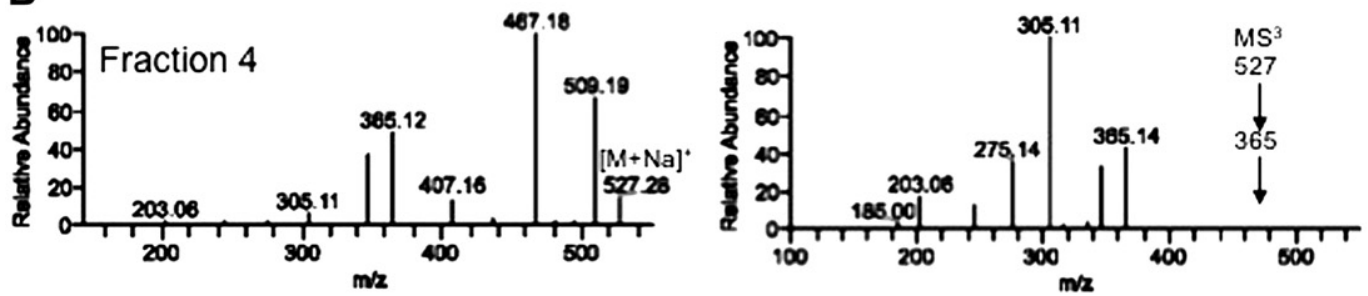

C
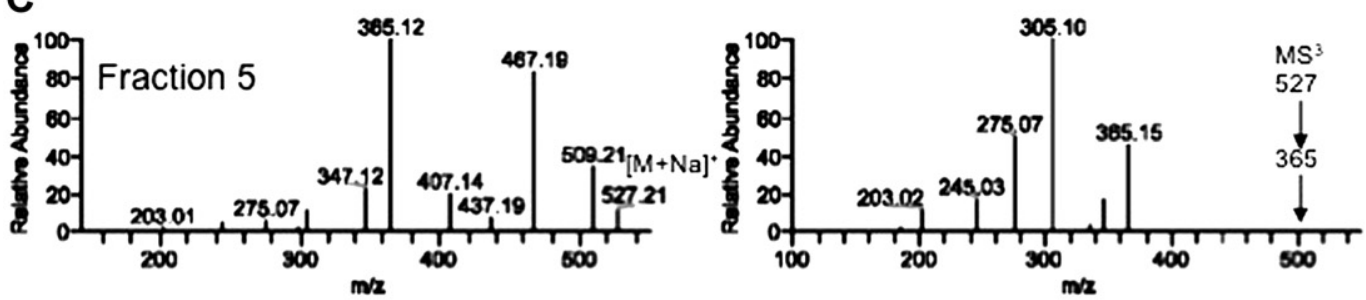

D
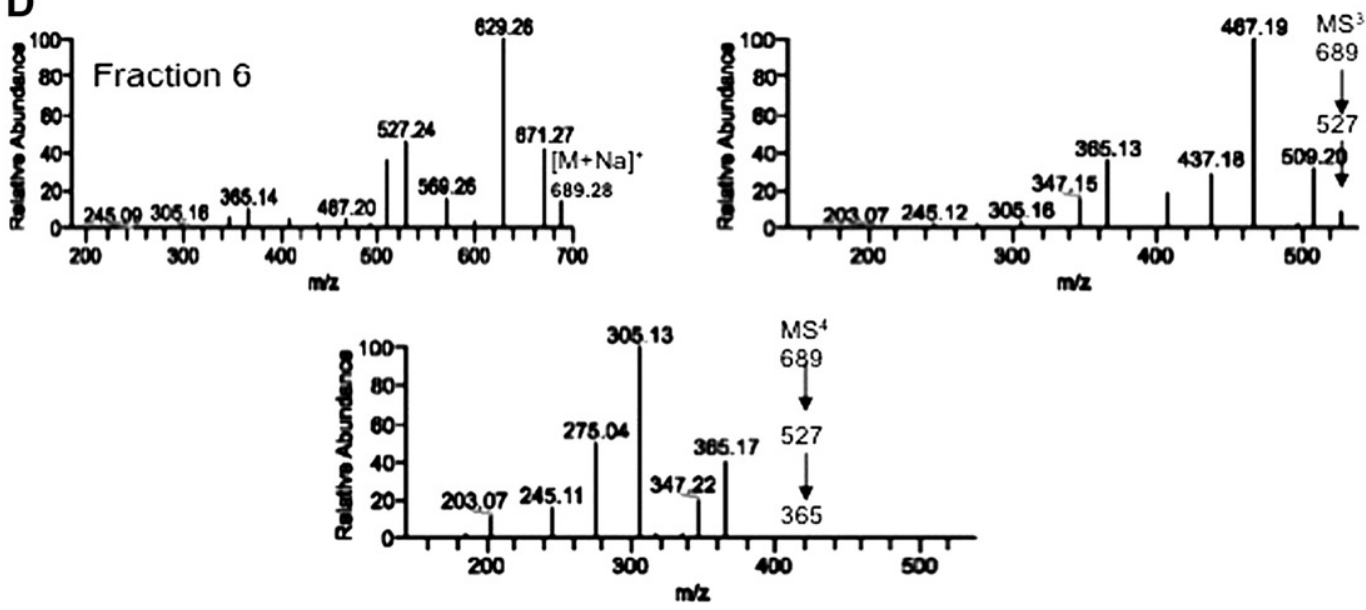

Fig. 4. ESI-MS spectra of the oligosaccharide that eluted respectively in: (A) fraction 3 ( $m / z$ 365); (B) fraction 4 ( $m / z 527)$; (C) fraction 5 ( $m / z 527$ ); (D) fraction 6 ( $m / z 689$ ). 
crosslinked concanavalin A- $\beta$-galactosidase a retention of $95 \%$ activity after seven repeated uses (Haider \& Husain, 2007) was observed, IgG-cellulose immobilized $\beta$-galactosidase $46 \%$ of the initial activity remained after 10 uses (Haider \& Husain, 2009) and chitosan (Gaur et al., 2006) observed a decrease of more than $20 \%$ in the enzyme activity was observed after four uses.

Overall, these results confirm the efficiency of magnetic supports for the immobilization of $\beta$-galactosidase.

\subsection{Characterization of GOS}

The oligosaccharides that eluted in fractions 3, 4, 5 and 6 were characterized by ESI-MS. In the corresponding ESI-MS spectra it was possible to identify the peaks corresponding to the $[\mathrm{M}+\mathrm{Na}]^{+}$ ions of the eluted oligosaccharides, which permitted the determination of molecular weights. When analyzing these results, it must considered that the presence of one peak does not confirm that only one oligosaccharide was eluted, as different carbohydrates of the same molecular weight can be present, The ESI-MS spectrum of fraction 3 showed an ion at $m / z 365$, corresponding to a hexose disaccharide, while the ESI-MS spectra of fractions 4 and 5 showed an ion at $m / z 527$, suggesting that trimers of hexoses were eluted in these peaks. For fraction 6 , an ion at $\mathrm{m} / \mathrm{z} 689$ was identified, allowing the identification of tetramers of hexoses.

ESI-MS/MS experiments were conducted for the $\left[\mathrm{Hex}_{n}+\mathrm{Na}\right]^{+}$ ion $(n=2-4)$ in each fraction, to confirm their monosaccharide composition. The ion at $m / z 365\left(\left[\mathrm{Hex}_{2}+\mathrm{Na}\right]^{+}\right)$of the disaccharide eluted in fraction 3 fragmented by the loss of a hexose residue ( $-162 \mathrm{Da}$ ), yielding an ion at $m / z 203$ (Fig. 4A), that corresponded to an $[\mathrm{Hex}+\mathrm{Na}]^{+}$ion. Also, the presence of the product ions at $m / z$ 305,275 and 245 resulted from the cross ring fragmentation of two glucose units linked by a $1 \rightarrow 6$ type linkage, as previously described (Zaia, 2004). This information is in agreement with the results inferred by the HPLC elution pattern, that suggest a different structure between the lactose (fraction 2), which has two hexose units linked by a $1 \rightarrow 4$ linkage, and that of the disaccharide eluting in fraction 3. This, according with the MS/MS results, has two hexose units linked by a $1 \rightarrow 6$ linkage.

The ESI-MS/MS spectra of the trisaccharides, with $[\mathrm{M}+\mathrm{Na}]^{+}$ ion at $m / z 527$, eluting in fractions 4 and 5 (Fig. 4B and C) showed major product ions formed by the loss of one and two hexose units (ions at $m / z 365$ and 203, respectively). This fragmentation pattern allowed the conclusion that the trisaccharides were composed of three hexose units. Also, the ESI-MS/MS spectra of these trisaccharides present in fractions 4 and 5 were slightly different, suggesting that they have dissimilar structures. For the GOS eluted in fraction 4, the presence of major fragment ions at $\mathrm{m} / \mathrm{z} 467$ and $\mathrm{m} / \mathrm{z} 407$, that were formed by the loss of $60 \mathrm{Da}$ $\left(-\mathrm{C}_{2} \mathrm{H}_{4} \mathrm{O}_{2}\right)$ and $120 \mathrm{Da}\left(-\mathrm{C}_{4} \mathrm{H}_{8} \mathrm{O}_{4}\right)$, suggested the presence of a $1 \rightarrow 4$ linkage, most probably at the reducing end. Also, the sequential fragmentation $\left(\mathrm{MS}^{3}\right)$ of the product ion at $\mathrm{m} / \mathrm{z} 365$ $\left(\left[\mathrm{Hex}_{2}+\mathrm{Na}\right]^{+}\right)$showed product ions due to cross ring cleavages by losses of 60, 90 and $120 \mathrm{Da}$, indicating that these two monomers are linked by a $1 \rightarrow 6$ linkage. Together, the MS/MS results from the compound in fraction 4 suggested that this must have a $1 \rightarrow 4$ and a $1 \rightarrow 6$ linkage, the first at the reducing end. In opposition, the ESI-MS/MS spectrum of the trisaccharide in fraction 5 (Fig. 4C) showed a small ion at $m / z 437$ along with ions at $m / z 467$ and 407 . Although this fragment ion suggests the presence of a $1 \rightarrow 6$ linkage at the reducing end of the molecule, its low abundance makes this hypothesis unproven. Nevertheless, the presence of a $1 \rightarrow 6$ linkage in this trisaccharide was confirmed by the $\mathrm{MS}^{3}$ spectra of its product ion at $m / z 365$. Thus, although MS/MS analysis did not allow the correct assignment of the type of linkages present in this trisaccharide, it indicated that the two trisaccharides had distinct structures.

With respect to the tetrasaccharide eluted in fraction 6 , the fragmentation of its $[\mathrm{M}+\mathrm{Na}]^{+}$ion at $m / z 689$ was obtained by the loss of one, two and three hexose units, forming the product ions $\left[\mathrm{Hex}_{3}+\mathrm{Na}\right]^{+},\left[\mathrm{Hex}_{2}+\mathrm{Na}\right]^{+},[\mathrm{Hex}+\mathrm{Na}]^{+}$at $m / z 527$ and 365 respectively. This data confirmed that the compound was a tetramer of hexose units. Moreover, the analysis of the $\mathrm{MS}^{3}$ spectra of the referred product ions (data not shown) indicated that this tretramer had a $1 \rightarrow 4$ linkage at the reducing end and two other $1 \rightarrow 6$ linkages.

The NMR analysis of fractions 4,5 and 6 confirmed the results from the mass spectrometry analysis and permitted the determination of the detailed structure of the eluted compounds. It should

Table 2

${ }^{1} \mathrm{H}$ and ${ }^{13} \mathrm{C}$ chemical shifts $\left(\delta\right.$, ppm) of $\mathrm{D}_{2} \mathrm{O}$ solutions of the synthesized galactooligosaccharides (fractions $4-6$ ).

\begin{tabular}{|c|c|c|c|c|c|c|c|}
\hline \multirow{2}{*}{$\begin{array}{l}\text { Galactooligo- } \\
\text { saccharide } \\
\text { residues }\end{array}$} & \multicolumn{7}{|c|}{ Chemical shifts $^{\mathrm{a}}$} \\
\hline & & 1 & 2 & 3 & 4 & 5 & 6 \\
\hline \multicolumn{8}{|l|}{ Fraction 4} \\
\hline $\mathrm{T}-\beta$-Galp $p^{\mathrm{b}}$ & ${ }^{1} \mathrm{H}$ & 4.49 & 3.56 & 3.68 & 3.98 & 3.95 & 4.08 \\
\hline \multicolumn{8}{|c|}{$(J=7.9$ and $1.6 \mathrm{~Hz})$} \\
\hline & ${ }^{13} \mathrm{C}$ & 106.2 & 73.9 & 75.3 & 71.3 & 76.9 & 71.9 \\
\hline \multirow[t]{3}{*}{$6-\beta$-Galp- $\left(1 \rightarrow^{\mathrm{c}}\right.$} & \multirow{2}{*}{\multicolumn{7}{|c|}{$(J=8.0 \mathrm{~Hz})$}} \\
\hline & & & & & & & \\
\hline & ${ }^{13} \mathrm{C}$ & 106.0 & 73.7 & 75.5 & 71.5 & 78.0 & 63.9 \\
\hline \multirow[t]{3}{*}{ 4- $\beta$-Glcp } & ${ }^{1} \mathrm{H}$ & 4.67 & 3.31 & 3.66 & 3.68 & 3.63 & 3.97 \\
\hline & \multicolumn{7}{|c|}{$(J=8.0 \mathrm{~Hz})$} \\
\hline & ${ }^{13} \mathrm{C}$ & 98.6 & 76.6 & 77.4 & 82.1 & 77.6 & 63.0 \\
\hline \multirow[t]{3}{*}{ 4- $\alpha$-Glcp } & ${ }^{1} \mathrm{H}$ & 5.23 & 3.60 & 3.83 & 3.68 & 3.97 & 3.89 \\
\hline & \multicolumn{7}{|c|}{$(J=3.7 \mathrm{~Hz})$} \\
\hline & ${ }^{13} \mathrm{C}$ & 94.7 & 73.9 & 74.5 & 82.3 & 72.8 & 62.9 \\
\hline \multicolumn{8}{|l|}{ Fraction 5} \\
\hline \multirow[t]{3}{*}{$\mathrm{T}-\beta-$ Gal $p^{\mathrm{d}}$} & ${ }^{1} \mathrm{H}$ & 4.46 & 3.56 & 3.66 & 3.93 & 3.72 & 3.79 \\
\hline & & \multicolumn{6}{|c|}{$(J=7.8$ and $5.4 \mathrm{~Hz})$} \\
\hline & ${ }^{13} \mathrm{C}$ & 106.0 & 73.5 & 75.4 & 71.6 & 78.0 & 63.9 \\
\hline \multirow[t]{3}{*}{$\mathrm{T}-\beta-\mathrm{Gal} p^{\mathrm{c}}$} & ${ }^{1} \mathrm{H}$ & 4.51 & 3.56 & 3.66 & 3.93 & 3.72 & 3.79 \\
\hline & \multicolumn{7}{|c|}{$(J=7.8 \mathrm{~Hz})$} \\
\hline & ${ }^{13} \mathrm{C}$ & 105.7 & 73.8 & 75.6 & 71.6 & 78.1 & 63.9 \\
\hline \multirow[t]{3}{*}{$4,6-\beta$-Glcp } & \multirow{2}{*}{\multicolumn{7}{|c|}{$(J=5.7 \mathrm{~Hz})$}} \\
\hline & & & & & & & \\
\hline & ${ }^{13} \mathrm{C}$ & 98.8 & 76.5 & 76.6 & 80.8 & 77.2 & 70.4 \\
\hline \multirow[t]{3}{*}{ 4,6- $\alpha$-Glcp } & ${ }^{1} \mathrm{H}$ & 5.23 & 3.60 & 3.84 & 3.77 & 3.91 & 4.29 \\
\hline & \multicolumn{7}{|c|}{$(J=3.7 \mathrm{~Hz})$} \\
\hline & ${ }^{13} \mathrm{C}$ & 94.8 & 74.0 & 74.2 & 80.8 & 73.7 & 70.4 \\
\hline \multicolumn{8}{|l|}{ Fraction 6} \\
\hline \multirow[t]{3}{*}{$\mathrm{T}-\beta-$ Galp $p^{\mathrm{b}}$} & ${ }^{1} \mathrm{H}$ & 4.51 & 3.56 & 3.66 & 3.97 & 3.71 & 3.78 \\
\hline & & \multicolumn{6}{|c|}{$(J=7.7 \mathrm{~Hz})$} \\
\hline & ${ }^{13} \mathrm{C}$ & 106.0 & 73.6 & 75.7 & 71.5 & 78.0 & 63.9 \\
\hline $6-\beta$-Galp- $\left(1 \rightarrow^{\mathrm{b}, *}\right.$ & ${ }^{1} \mathrm{H}$ & 4.46 & 3.56 & 3.67 & 3.97 & 3.93 & 4.06 \\
\hline \multirow[t]{4}{*}{$6-\beta$-Galp- $\left(1 \rightarrow^{\mathrm{c}, *}\right.$} & ${ }^{1} \mathrm{H}$ & 4.47 & 3.56 & 3.67 & 3.92 & 3.91 & 4.06 \\
\hline & & \multicolumn{6}{|c|}{$(J=7.8 \mathrm{~Hz}) /(J=7.7 \mathrm{~Hz})$} \\
\hline & ${ }^{13} \mathrm{C}$ & 106.2 & 73.7 & 75.3 & 71.3 & 76.8 & 72.0 \\
\hline & ${ }^{13} \mathrm{C}$ & 106.3 & 73.7 & 75.4 & 71.5 & 76.6 & 72.1 \\
\hline $4-\beta-G l c p$ & ${ }^{1} \mathrm{H}$ & 4.68 & 3.31 & 3.66 & 3.68 & 3.63 & 3.96 \\
\hline & & $U=8.0$ & & & & & \\
\hline & ${ }^{13} \mathrm{C}$ & 98.6 & 76.6 & 77.4 & 82.0 & 77.6 & 63.1 \\
\hline 4- $\alpha$-Glcp & ${ }^{1} \mathrm{H}$ & 5.23 & 3.61 & 3.85 & 3.68 & 3.97 & 3.89 \\
\hline & & $U=3.7$ & & & & & \\
\hline & ${ }^{13} \mathrm{C}$ & 94.7 & 73.9 & 74.5 & 82.3 & 72.9 & 62.9 \\
\hline
\end{tabular}

a Assignments done in accordance to the data in the proton $\left({ }^{1} \mathrm{H}\right.$ NMR $)$, carbon $\left({ }^{13} \mathrm{C}\right.$ NMR), homonuclear shift correlation with presaturation during relaxation delay (COSY), heteronuclear single quantum coherence (HSQC) and heteronuclear multiple quantum coherence (HMBC) spectra.

${ }^{\mathrm{b}}$ Residue linked to the $0-6$ of Galp (an asterisk indicates that most of the chemical shifts of these two sugar residues were not possible to discriminate).

${ }^{c}$ Residue linked to the $0-4$ of Glcp (an asterisk indicates that most of the chemical shifts of these two sugar residues were not possible to discriminate).

${ }^{\mathrm{d}}$ Residue linked to the $0-6$ of Glcp. 
be noted that the NMR spectra of each fraction only presented signals corresponding to one compound, suggesting that single GOSs were collected in fractions 4, 5 and 6. For each oligosaccharide, the ${ }^{1} \mathrm{C}$ and ${ }^{13} \mathrm{C}$ chemical shifts were assigned by the interpretation of their ${ }^{1} \mathrm{H}$ NMR, ${ }^{13} \mathrm{C}$ NMR, HSQC, COSY and HMBC spectra (data not shown) and by further comparison with those of lactose and to the literature (Bock, Pedersen, \& Pedersen, 1984; Kimura, Matsumoto, Ishihara, Harada, \& Miyagi, 1995; Yanahira et al., 1995). Accordingly, the compound eluted in fraction 4 showed characteristic ${ }^{1} \mathrm{H}$ and ${ }^{13} \mathrm{C}$ chemical shifts for $\mathrm{T}-\beta$-Galp $\left(\delta_{\mathrm{H}-1}=4.47 \mathrm{ppm}, J=8.0, \delta_{\mathrm{C}-1}=106.0 \mathrm{ppm}\right), 4-\beta$-Glcp $\left(\delta_{\mathrm{H}-1}=\right.$ $\left.4.67 \mathrm{ppm}, J=8.0 \mathrm{~Hz}, \delta_{\mathrm{C}-1}=98.6 \mathrm{ppm}\right)$ and $4-\alpha$-Glcp monomers $\left(\delta_{\mathrm{H}-1}=5.23 \mathrm{ppm}, J=3.7 \mathrm{~Hz}, \delta_{\mathrm{C}-1}=94.7 \mathrm{ppm}\right)$ (Table 2$)$. Also, the remaining ${ }^{13} \mathrm{C}$ resonances in its ${ }^{13} \mathrm{C}$ NMR spectrum at 106.2, 73.9, $75.3,71.3,76.9$ and $71.9 \mathrm{ppm}$, as their corresponding ${ }^{1} \mathrm{H}$ resonances in the ${ }^{1} \mathrm{H}$ NMR spectrum $[4.49 \mathrm{~J}=7.9$ and $1.6 \mathrm{~Hz}), 3.56,3.68,3.98$, 3.95 and $4.08 \mathrm{ppm}$ ], indicated the presence of an internal $6-\beta$-Galp$(1 \rightarrow$ residue). Thus, these results permitted the conclusion that the compound eluted in fraction 4 was a $\beta$-D-Galp- $(1 \rightarrow 6)-\beta$-D-Galp$(1 \rightarrow 4)$-Glcp.

The trisaccharide in fraction 5 was identified as $\beta$-D-Galp$(1 \rightarrow 4)-[\beta$-D-Galp- $(1 \rightarrow 6)]-G l c p$. In accordance to this, the C-6 and H-6 resonances of the Glcp sugar unit (70.4 ppm and 4.29/4.22 ppm for the $\alpha$ and $\beta$ anomers) were deshielded compared with those of lactose $(62.8 / 62.9 \mathrm{ppm}$ and $3.72 / 3.81$ and $3.69 \mathrm{ppm})$ and two T- $\beta$ Galp sugar units $\left(\delta_{\mathrm{H}-1}=4.51 \mathrm{ppm}, J=7.8 \mathrm{~Hz} ; \delta_{\mathrm{H}-1}=4.46 \mathrm{ppm}\right.$, $J=7.8$ and $5.4 \mathrm{~Hz}$ ) were detected.

NMR data from fraction 6 indicated the presence of the tetrasaccharide $\beta$-D-Galp-( $1 \rightarrow 6)-\beta$-D-Galp- $(1 \rightarrow 6)-\beta$-D-Gal $p$ - $(1 \rightarrow 4)-G l c p$. The chemical shifts of the two internal $\beta$-galactosyl residues could only be discriminated for their $\mathrm{H}-1 / \mathrm{C}-1$ signals $\left(\delta_{\mathrm{H}-1}=4.46 \mathrm{ppm}\right.$, $\left.J=7.8 \mathrm{~Hz} ; \delta_{\mathrm{C}-1}=106.2 \mathrm{ppm}\right)$ for the $6-\beta$-Galp- $(1 \rightarrow$ sugar unit linked to the $0-6$ of a $\beta$-Galp $)$ and $\left(\delta_{\mathrm{H}-1}=4.47 \mathrm{ppm}, J=7.7 \mathrm{~Hz}\right.$; $\left.\delta_{\mathrm{C}-1}=106.3 \mathrm{ppm}\right)$ for the $6-\beta$-Galp- $(1 \rightarrow$ sugar unit linked to the $0-4$ to the Glcp residue), as these two sugar units have a similar chemical environment.

\section{Conclusion}

A magnetic and immobilized preparation of $\beta$-galactosidase from A. oryzae capable of producing GOS with yields comparable to other systems was synthesized by using an inexpensive and simple methodology. It also allowed for a straight forward and rapid separation of the reaction medium from the catalyst, making possible an effective control of the reaction time. Moreover, it retained $90 \%$ of its initial activity after ten runs. Fractionation of the GOS mixture allowed the identification of glucose, galactose, lactose and one hexose disaccharide with a $1 \rightarrow 6$ linkage. The GOS were identified as two trisaccharides ( $\beta$-D-Galp- $(1 \rightarrow 6)-\beta$-D-Galp$(1 \rightarrow 4)$-Glcp and $\beta$-D-Galp- $(1 \rightarrow 4)-[\beta$-D-Galp- $(1 \rightarrow 6)]-G l c p)$ and one tetrasaccharide ( $\beta$-D-Galp- $(1 \rightarrow 6)-\beta$-D-Galp- $(1 \rightarrow 6)-\beta$-D-Galp$(1 \rightarrow 4)$-Glcp). The composition of the obtained GOS mixture and, above all, its chemical and structural composition will contribute not only to the development of advanced fractionation/separation processes of the different GOS but will also play an important role in the understanding of the mechanisms associated with the prebiotic properties of the GOS.

\section{Acknowledgements}

David F.M. Neri gratefully acknowledges support by Alban, the European Union Programme of High Level Scholarships for Latin America (Scholarship No. E05D057787BR). Luiz B. Carvalho Jr. is recipient of a scholarship from the Brazilian National Research Council (CNPq). M.R.M. Domingues acknowledges financial support provided to the project POCI/QUI/59337/2004. Duarte P. M. Torres acknowledges Fundação para a Ciência e a Tecnologia (Portugal) for the PhD Grant received (reference SFRH/BDE/15510/2004).

\section{References}

Alander, M., Mättö, J., Kneifel, W., Johansson, M., Kögler, B., Crittenden, R., et al. (2001). Effect of galacto-oligosaccharide supplementation on human faecal microflora and on survival and persistence of Bifidobacterium lactis Bb-12 in the gastrointestinal tract. International Dairy Journal, 11, 817-825.

Albayrak, N., \& Yang, S. T. (2002). Production of galacto-oligosaccharides from lactose by Aspergillus oryzae $\beta$-galactosidase immobilized on cotton cloth. Biotechnology and Bioengineering, 77, 8-19.

Amaral, I., Carneiro-da-Cunha, M. G., Carvalho, L. B., Jr., \& Bezerra, R. S. (2006). Fish trypsin immobilized on ferromagnetic Dacron. Process Biochemistry, 41, 1213-1216.

Aslan, Y., \& Tanrıseven, A. (2007). Immobilization of Pectinex Ultra SP-L to produce galactooligosaccharides. Journal of Molecular Catalysis B: Enzymatic, 45, 73-77.

Bayramoglu, G., Tunali, Y., \& Arica, M. Y. (2007). Immobilization of $\beta$-galactosidase onto magnetic poly(GMA-MMA) beads for hydrolysis of lactose in bed reactor. Catalysis Communication, 8, 1094-1101.

Bock, K., Pedersen, C., \& Pedersen, H. (1984). Carbon-13 nuclear magnetic resonance data for oligosaccharides. Advances Carbohydrate Chemistry and Biochemistry, 42, $193-225$.

Boehm, G., \& Stahl, B. (2007). Oligosaccharides from milk. Journal of Nutrition, 137, $847-849$.

Carneiro-Leão, A. M. A., Oliveira, E. A., \& Carvalho, L. B., Jr. (1991). Immobilization of protein on ferromagnetic Dacron. Applied Biochemistry and Biotechnology, 31, 53-58.

Cheng, T. C., Duan, K. J., \& Sheu, D. C. (2006). Application of tris(hydroxymethyl) phosphine as a coupling agent for $\beta$-galactosidase immobilized on chitosan to produce galactooligosaccharides. Journal of Chemical Technology and Biotechnology, 81, 233-236.

Dias, L. G., Veloso, A. C. A., Correia, D. M., Rocha, O., Torres, D. K., Rocha, I., et al. (2009). UV spectrophotometry method for the monitoring of galactooligosaccharides production. Food Chemistry, 113, 246-252.

Dourado, F., Cardoso, S. M., Silva, A. M. S., Gama, F. M., \& Coimbra, M. A. (2006). NMR structural elucidation of the arabinan from Prunus dulcis immunobiological active pectic polysaccharides. Carbohydrate Polymers, 66, 27-33.

Gänzle, M. G., Haase, G., \& Jelen, P. (2008). Lactose - crystallization, hydrolysis and value-added derivatives. International Dairy Journal, 18, 685-694.

Gaur, R., Pant, H., Jain, R., \& Khare, S. K. (2006). Galacto-oligosaccharide synthesis by immobilized Aspergillus oryzae $\beta$-galactosidase. Food Chemistry, 97, 426-430.

Haider, T., \& Husain, Q. (2007). Calcium alginate entrapped preparations of Aspergillus oryzae $\beta$-galactosidase: its stability and applications in the hydrolysis of lactose. International Journal of Biological Macromolecules, 41, 72-80.

Haider, T., \& Husain, Q. (2009). Immobilization of $\beta$-galactosidase from Aspergillus oryzae via immunoaffinity support. Biochemical Engineering Journal, 43, 307-314.

Hsu, C. A., Lee, S. L., \& Chou, C. C. (2007). Enzymatic production of galactooligosaccharides by $\beta$-galactosidase from Bifidobacterium longum BCRC 15708. Journal of Agricultural and Food Chemistry, 55, 2225-2230.

Ishikawa, F., Takayama, H., Matsumoto, K., Ito, M., Chonan, O., Deguchi, Y., et al. (1995). Effects of $\beta-1-4$ linked galacto-oligosaccharides on human fecal microflora. Bixdus, 9, 5-18, (in Japanese).

Ito, M., Deguchi, Y., Matsumoto, K., Kimura, M., Onodera, N., \& Yajima, T. (1993). Influence of galactooligosaccharides on the human fecal microflora. Journal of Nutritional Science and Vitaminology, 39, 635-640.

Ito, M., Deguchi, Y., Myamori, A., Matsumoto, K., Kikuchi, H., Matsumoto, K., et al. (1990). Effects of administration of galactooligosaccharides on the human fecal microflora, stool weight and abdominal sensation. Microbial Ecology in Health and Disease, 3, 285-292.

Kimura, K., Matsumoto, K., Ishihara, C., Harada, K., \& Miyagi, A. (1995). Structure determination of galacto-oligosaccharides by pyridylamination and NMR spectroscopy. Carbohydrate Research, 270, 33-42.

Kondo, A., \& Fukuda, H. (1997). Preparation of thermo-sensitive magnetic hydrogel microspheres and application to enzyme immobilization. Journal of Fermentation and Bioengineering, 84, 337-341.

Li, Z., Xiao, M., Lu, L., \& Li, Y. (2008). Production of non-monosaccharide and highpurity galactooligosaccharides by immobilized enzyme catalysis and fermentation with immobilized yeast cells. Process Biochemistry, 43, 896-899.

Mahoney, R. R. (1998). Galactosyl-oligosaccharide formation during lactose hydrolysis: a review. Food Chemistry, 63, 147-154.

Maischberger, T., Nguyen, T., Sukyai, P., Kittl, R., Riva, S., Ludwig, R., et al. (2008). Production of lactose-free galacto-oligosaccharide mixtures: comparison of two cellobiose dehydrogenases for the selective oxidation of lactose to lactobionic acid. Carbohydrate Research, 343, 2140-2147.

Martínez-Villaluenga, C., Cardelle-Cobas, A., Corzo, N., Olano, A., \& Villamiel, M. (2008). Optimization of conditions for galactooligosaccharide synthesis during lactose hydrolysis by $\beta$-galactosidase from Kluyveromyces lactis (Lactozym 3000 L HP G). Food Chemistry, 107, 258-264. 
Mozaffar, Z., Nakanishi, K., Matsuno, R., \& Kamikubo, T. (1984). Purification and properties of $\beta$-galactosidase from Bacillus circulans. Agricultural and Biological Chemistry, 48, 3053-3061.

Mussatto, S. I., \& Mancilha, I. M. (2007). Non-digestible oligosaccharides: a review. Carbohydrate Polymers, 68, 587-597.

Neri, D. F. M., Balcão, V. M., Carneiro-da-Cunha, M. G., Carvalho, L. B., Jr., \& Teixeira, J. A. (2008). Immobilization of $\beta$-galactosidase from Kluyveromyces lactis onto a polysiloxane-polyvinyl alcohol magnetic (mPOS-PVA) composite for lactose hydrolysis. Catalysis Communication, 9, 2334-2339.

Neri, D. F. M., Balcão, V. B., Costa, R. S., Rocha, I. C. A. P., Ferreira, E. M. F. C. Torres, D. P. M., et al. (2009a). Galacto-oligosaccharides production during lactose hydrolysis by free Aspergillus oryzae $\beta$-galactosidase and immobilized on magnetic polysiloxane-polyvinyl alcohol. Food Chemistry, 115, 92-99.

Neri, D. F. M., Balcão, V. B., Dourado, F. O. Q., Oliveira, J. M. B., Carvalho, L. B., Jr., \& Teixeira, J. A. (2009b). Galactooligosaccharides production by $\beta$-galactosidase immobilized onto magnetic polysiloxane-polyaniline particles. Reactive and Functional Polymers, 69, 246-251.
Ozawa, O., Ontsuka, K., \& Uchidat. (1989). Production of 4'-galactosyllactose by intact and immobilized cells of Cryptococcus laurentii OKN-4. Journal Japanese Society for Food Science and Technology, 36, 325-328.

Sako, R., Matsumoto, K., \& Tanaka, R. (1999). Recent progress on research and applications of non-digestible galacto-oligosaccharides. International Dairy Journal, 9, 69-80.

Shin, H. J., Park, J. M., \& Yang, J. W. (1998). Continuous production of galactooligosaccharides from lactose by Bullera singularis $\beta$-galactosidase immobilized in chitosan beads. Process Biochemistry, 33, 787-792.

Tannock, G. W., Munro, K., Bibiloni, R., Simon, M.A., Hargreaves, P., Gopal, P., et al. (2004). Impact of the consumption of oligosaccharide-containing biscuits on the fecal microbiota of humans. Applied and Environmental Microbiology, 70, 2129-2136.

Yanahira, S., Kobayashi, T., Suguri, T., Nakakoshi, M., Miura, S., Ishikawa, H., et al. (1995). Formation of oligosaccharides from lactose by Bacillus circulans $\beta$ galactosidase. Bioscience, Biotechnology and Biochemistry, 59, 1021-1026.

Zaia, J. (2004). Mass spectrometry of oligosaccharides. Mass Spectrometry Reviews, 23, 161-227. 